\section{DEPRESSION OF CARDIAC FUNCTION AFTER DEEP HYPOTHERMIC CIRCULATORY ARREST IN DEEPLY ANESTHETIZED NEONATAL LAMBS}

Cardiac dysfunction is common after neonatal cardiac operations. Previous in vivo studies in neonatal animal models however, have failed to demonstrate decreased left ventricular function after ischemia and reperfusion. Cardiac dysfunction may have been masked in these studies by increased endogenous catecholamine levels associated with the use of light halothane anesthesia. Currently, neonatal cardiac operations are often performed with deep opiate anesthesia, which suppresses catecholamine surges and may affect functional recovery. We therefore examined the recovery of left ventricular function after ischemia and reperfusion in neonatal lambs anesthetized with high-dose fentanyl citrate $(450 \mu \mathrm{g} / \mathrm{kg}$ administered intravenously). Seven intact neonatal lambs with open-chest preparation were instrumented with left atrial and left ventricular pressure transducers, left ventricular dimension crystals, and a flow transducer. The lambs were cooled $\left(<18^{\circ} \mathrm{C}\right)$ on cardiopulmonary bypass $(22 \pm 6$ minutes), exposed to deep hypothermic circulatory arrest (46 \pm 1 minutes), and rewarmed on cardiopulmonary bypass $(30 \pm 10$ minutes $)$. Catecholamine levels and indexes of left ventricular function were determined before (baseline) and 30, 60, 120, 180, and 240 minutes after termination of cardiopulmonary bypass. Levels of epinephrine, norepinephrine, and dopamine were unchanged from baseline values. Left ventricular contractility (slope of end-systolic pressure-volume relationship) was depressed from baseline value $(31.7 \pm 9.3 \mathrm{~mm} \mathrm{Hg} / \mathrm{ml})$ at 30 minutes $(15.7 \pm 6.4 \mathrm{~mm} \mathrm{Hg} / \mathrm{ml})$ and 240 minutes $(22.7 \pm 6.4 \mathrm{~mm} \mathrm{Hg} / \mathrm{ml})$ but unchanged between 60 and 180 minutes. Left ventricular relaxation (time constant of isovolumic relaxation) was prolonged from baseline value $(19.0 \pm 3.0 \mathrm{msec})$ at 30 minutes $(31.4 \pm 10.0 \mathrm{msec})$ and 240 minutes $(22.1 \pm 2.8 \mathrm{msec})$ but unchanged between 60 and 180 minutes. Afterload (left ventricular end-systolic meridional wall stress) was decreased at 30, 60, and 240 minutes. Indexes of global cardiac function (cardiac output, stroke volume), preload (enddiastolic volume), and left ventricular compliance (elastic constant of end-diastolic pressure-volume relationship) were unchanged from baseline values. In deeply anesthetized neonatal lambs exposed to ischemia and reperfusion, left ventricular contractility, relaxation, and afterload are markedly but transiently depressed early after reperfusion and mildly depressed late after reperfusion. (J THORAC CARDIOvasC SuRg 1996;111: 359-66)

Harm Velvis, MD, ${ }^{a}$ Michael H. Hines, MD, ${ }^{b}$

H. Sidney Klopfenstein, MD, PhD, ${ }^{\mathrm{c}}$ David D. Berry, $\mathrm{MD},{ }^{\mathrm{a}}$ and Jakob Vinten-Johansen, PhD, ${ }^{\mathrm{b}}$ Winston-Salem, N.C.
From the Departments of Pediatrics, ${ }^{\mathrm{a}}$ Cardiothoracic Surgery, ${ }^{\mathrm{b}}$ and Internal Medicine, ${ }^{c}$ Bowman Gray School of Medicine, Wake Forest University, Winston-Salem, N.C.

Received for publication March 7, 1995.

Accepted for publication May 18, 1995.
Address for reprints: Harm Velvis, MD, Department of Pediatrics, Section of Cardiology, Bowman Gray School of Medicine, Wake Forest University, Medical Center Blvd., WinstonSalem, NC 27157-1081.

Copyright (C) 1996 by Mosby-Year Book, Inc.

$0022-5223 / 96 \$ 5.00+0 \quad \mathbf{1 2 / 1 / 6 6 3 3 4}$ 
W th increasing frequency, surgical correction of congenital heart disease is being performed in the neonatal period. ${ }^{1-3}$ Early corrective surgery avoids the need for palliative procedures and limits the duration of chronic cyanosis or ventricular overload. Early corrective operations are technically more challenging, however, and expose immature neonatal hearts to ischemia and reperfusion, to which they have unique responses. Most studies indicate better functional recovery after ischemia and reperfusion in immature hearts than in mature hearts. ${ }^{4-9}$ The time between onset of ischemia and onset of contracture, however, is generally decreased in immature hearts. ${ }^{4,10,11}$ Also, the immature heart may be particularly susceptible to perfusion cooling in the nonarrested state. ${ }^{12,13}$ Finally, the efficacy of cardioplegia protection strategies is more variable in neonates. ${ }^{6,7,14-17}$ Most of these studies were performed in isolated hearts, and relatively few studies examined recovery from ischemia-reperfusion injury in intact neonatal animal models. ${ }^{18-23}$ In intact neonatal lambs and piglets exposed to 60 to 120 minutes of hypothermic global ischemia and 45 to 90 minutes of reperfusion, left ventricular (LV) compliance has previously been reported to be normal ${ }^{20}$ or depressed, ${ }^{18,21}$ and $\mathrm{LV}$ contractility has been reported to be normal ${ }^{19,21,23}$ or enhanced. ${ }^{18,20,22}$ These findings are inconsistent with the clinical observations of cardiac dysfunction and common need for cardiotonic drugs after operations for congenital heart disease. ${ }^{24}$ One important variable determining the functional outcome after ischemia is the level of circulating endogenous catecholamines. ${ }^{25}$ The use of light anesthesia in previous studies did not prevent cardiopulmonary bypass (CPB) and ischemia-related increases in the levels of circulating catecholamines, ${ }^{24}$ which in turn increased the inotropic state of the (stunned) myocardium $^{25}$ and therefore may have masked myocardial dysfunction. The current common use of deep opiate anesthesia, analgesia, and sedation both during and after neonatal cardiac operations suppresses catecholamine surges ${ }^{24}$ and may consequently unmask myocardial dysfunction after ischemia and reperfusion. We therefore tested the hypothesis that LV function is depressed after surgical ischemia and reperfusion in a model of deeply anesthetized intact neonatal lambs.

\section{Materials and methods}

Animals. Seven neonatal lambs (age $15 \pm 2$ days; weight $8.1 \pm 1.4 \mathrm{~kg}$ ) were studied. The lambs received humane care in compliance with the "Principles of Laboratory Animal Care" formulated by the National Society for Medical Research and the "Guide for the Care and Use of Laboratory Animals" prepared by the Institute of Laboratory Animal Resources and published by the National Institutes of Health (NIH Publication No. 86-23, revised 1985). The study protocol was approved by the Institutional Animal Care and Use Committee.

Surgery. Surgery was performed with the animals anesthetized with fentanyl citrate $(300 \mu \mathrm{g} / \mathrm{kg}$ administered intravenously for induction, $50 \mu \mathrm{g} / \mathrm{kg}$ supplemented intravenously every hour) and ketamine hydrochloride (20 $\mathrm{mg} / \mathrm{kg}$ administered intravenously for induction, $5 \mathrm{mg} / \mathrm{kg}$ supplemented intravenously every hour). The lambs were ventilated by volume-cycled respirator with oxygen-enriched room air. Polyvinyl catheters were placed in the femoral vein for delivery of fluids and drugs and in the femoral artery for pressure measurements.

After a median sternotomy, the pericardium was widely incised and tented. Solid-state pressure transducers (Konigsberg Instruments, Inc., Pasadena, Calif.) and fluidfilled catheters for transducer calibration were placed into the LV through the LV apex and into the left atrium through the left atrial appendage. Before operation, the pressure transducers were precisely calibrated at $39^{\circ} \mathrm{C}$ (normal body temperature for lambs). A fluid-filled catheter was also placed in the main pulmonary artery. Pairs of ultrasonic crystals (Triton Technology, San Diego, Calif.) were implanted to measure LV minor- and major-axis dimensions and LV wall thickness. An ultrasonic flowtransducer (Transonic Systems Inc., Ithaca, N.Y.) was placed around the pulmonary artery. Umbilical tape snares were placed loosely around the venae cavae. Finally, temperature probes (Sorin Biomedical, Irvine, Calif.) were placed in the nasopharynx, skin, and myocardium.

CPB, arrest, and cardioplegia. After acquisition of baseline data, a single $22 \mathrm{~F}$ venous return cannula was placed in the right atrium and a $10 \mathrm{~F}$ arterial cannula was placed in the ascending aorta. After systemic anticoagulation with $300 \mathrm{U} / \mathrm{kg}$ of heparin, the lambs were placed on total $\mathrm{CPB}$ with venous blood pumped through an infant membrane oxygenator (Sarns, 3M Health Care, Ann Arbor, Mich.) and oxygenated blood was returned with a roller pump. The pump was primed with a mixture of maternal packed erythrocytes and hetastarch (Hespan) to maintain a hematocrit of approximately $20 \%$. The flow rate was set at $150 \mathrm{ml} \cdot \mathrm{kg}^{-1} \cdot \mathrm{min}^{-1}$ and adjusted to maintain a mean arterial pressure of 40 to $50 \mathrm{~mm} \mathrm{Hg}$. A single $1 \mathrm{mg}$ phentolamine mesylate bolus was given and the lambs were cooled to $18^{\circ} \mathrm{C}$ nasopharyngeal temperature by perfusion cooling with a heat exchanger (Sarns) with supplemental topical cooling. When the target temperature had been achieved, the aorta was crossclamped, a single dose of $10 \mathrm{ml} / \mathrm{kg}$ cold $\left(4^{\circ} \mathrm{C}\right)$ crystalloid cardioplegia (Pledgisol) with a composition of $16 \mathrm{mmol} / \mathrm{L}$ potassium, $120 \mathrm{mmol} / \mathrm{L}$ sodium, $160 \mathrm{mmol} / \mathrm{L}$ chloride, 1.2 $\mathrm{mmol} / \mathrm{L}$ ionized calcium, $10 \mathrm{mmol} / \mathrm{L}$ bicarbonate, and 16 $\mathrm{mmol} / \mathrm{L}$ magnesium, an osmolarity of $324 \mathrm{mOsm} / \mathrm{L}$, and a $\mathrm{pH} 7.56$ at $37^{\circ} \mathrm{C}$ was delivered by antegrade hand injection into the aorta proximal to the crossclamp. The circulation was arrested and the blood volume collected in the blood reservoir. The myocardial temperature was kept 
below $10^{\circ} \mathrm{C}$ with topical saline ice slush. Deep hypothermic circulatory arrest was maintained for 45 minutes, after which the lambs were rewarmed on $\mathrm{CPB}$ to $37^{\circ} \mathrm{C}$ nasopharyngeal temperature and weaned from CPB without inotropic support. Only one lamb received a single dose of $100 \mathrm{mg} / \mathrm{kg}$ calcium gluconate in response to a low postCPB ionized calcium level $(1.00 \mathrm{mmol} / \mathrm{L})$. Post-CPB levels of ionized calcium were within normal limits but were slightly lower than pre-CPB levels $(1.31 \pm 0.18 \mathrm{mmol} / \mathrm{L}$ vs $1.50 \pm 0.27 \mathrm{mmol} / \mathrm{L} ; p<0.05$ ).

Data acquisition and analysis. Analog (Universal Signal Conditioners, RS3800 recorder; Gould Instrument Systems, Inc., Valley View, $\mathrm{OH}$ ) and digital (Memorex Telex 386 PC; Memorex Telex Corporation, Tulsa, Okla:; Spectrum Software, Bowman Gray School of Medicine, Winston-Salem, N.C., and Triton Technology, San Diego, Calif.) data were acquired at baseline before CPB and at 30,60, 120,180, and 240 minutes after termination of CPB. The fluid-filled catheters were connected to external transducers (Micro Switch, A Honeywell Division, Freeport, I11.) placed at midheart level and calibrated with a mercury-column sphygmomanometer. Digital data were acquired during transient respiratory apnea for 15 seconds at $200 \mathrm{~Hz}$ during steady-state conditions and during brief occlusions of the venae cavae to generate variably loaded pressure-volume loops. Data related to global, systolic, and diastolic LV function were averaged for each data file. Global LV function was assessed by cardiac output, stroke volume, and heart rate. LV systolic function was assessed by means of relatively load-independent pressure-volume relationship indexes. $\mathrm{LV}$ volume $\left(\mathrm{V}_{\mathrm{lv}}\right)$ was calculated according to the following formula:

$$
\mathrm{V}_{\mathrm{lv}}=\pi / 6 \cdot(\mathrm{D} 1 \cdot \mathrm{D} 2 \cdot \mathrm{D} 3)
$$

where $D 1$ and $D 2$ represent the $L V$ endocardial anteriorposterior dimension and D3 represents LV apex-base dimension. Relationships (ESPVRs) between end-systolic LV pressure $\left(\mathrm{P}_{\mathrm{es}}\right)$ and volume $\left(\mathrm{V}_{\mathrm{es}}\right)$ were determined according to the following formula ${ }^{26}$ :

$$
\mathrm{P}_{\mathrm{es}}=\mathrm{E}_{\mathrm{es}}\left(\mathrm{V}_{\mathrm{es}}-\mathrm{V}_{0}\right)
$$

where $E_{e s}$ is the slope of ESPVR (elastance) and $V_{o}$ is the volume intercept at zero pressure. Two components of $\mathrm{LV}$ diastolic function, LV rate of relaxation and LV compliance, were assessed. LV rate of relaxation was determined by calculating $\tau$, the time constant of isovolumic relaxation, according to the Weiss method ${ }^{27}$ :

$$
P_{(t)}=P_{(0)} e^{-t / \tau}
$$

where $P_{0}$ is the $\mathrm{LV}$ pressure at minimum $\mathrm{dP} / \mathrm{dt}, t$ is time after initial $t_{o}$, and $\tau$ is the time constant. LV compliance was determined by fitting $\mathrm{LV}$ end-diastolic pressures $\left(\mathrm{P}_{\mathrm{ed}}\right)$ and volumes $\left(\mathrm{V}_{\mathrm{ed}}\right)$ to the following exponential formula ${ }^{28}$ :

$$
P_{e d}=a \cdot e^{b \cdot v_{e d}}
$$

where $a$ is the pressure axis intercept at zero volume and $b$ is the $\mathrm{LV}$ end-diastolic elastic constant. $\mathrm{V}_{\mathrm{ed}}$, a measure of preload, was monitored and kept constant (with fluid infusions when needed) throughout the protocol. Afterload was assessed by calculating LV end-systolic meridional wall stress $\left(\mathrm{S}_{\mathrm{es}}\right)$ according to the following formula ${ }^{29}$ :

$$
\mathrm{S}_{\mathrm{es}}=\frac{1.332 \cdot \mathrm{P}_{\mathrm{es}} \cdot \mathrm{D}_{\mathrm{es}}}{4 \mathrm{H}_{\mathrm{es}} \cdot\left(1+\mathrm{H}_{\mathrm{es}} / \mathrm{D}_{\mathrm{es}}\right)}
$$

where $D_{e s}$ is the end-systolic endocardial anterior-posterior dimension and $H_{e s}$ is the end-systolic wall thickness calculated as follows:

$$
\frac{\text { Epicardial dimension }- \text { Endocardial dimension }}{2}
$$

Biochemical measurements. Arterial blood gases (ABL30; Radiometer Medical A/S, Copenhagen, Denmark) and hematocrits (MB Centrifuge; International Equipment Co., Needham Heights, Mass.) were obtained every 10 to 30 minutes. The $\alpha$-stat method was used for $\mathrm{pH}$ control. Arterial blood samples for catecholamine measurements were taken at baseline and at 60 and 240 minutes after termination of CPB. The blood samples were quickly transferred to chilled tubes containing ethyleneglycol-bis-( $\beta$-aminoethylether)- $N, N$, $N^{\prime}, N^{\prime}$-tetraacetic acid and centrifuged, the plasma was frozen at $-70^{\circ} \mathrm{C}$. The plasma samples were extracted with alumina and the concentrations of epinephrine, norepinephrine, and dopamine were determined by high-pressure liquid chromatographic electrochemical detection.

Statistical analysis. Statistical analysis was performed with Statistical Analysis Systems software for the personal computer (SAS Institute, Cary, N.C.). All data were summarized as means and standard deviations. Univariate repeated-measures analysis of variance for within subject effects and the Dunnett testing procedure were used to assess for differences from baseline values. ${ }^{30} \mathrm{~A} p$ value $<$ 0.05 was considered significant.

\section{Results}

Biochemical measurements. Measurements of $\mathrm{pH}$, carbon dioxide tension, and oxygen tension obtained after termination of CPB did not differ from baseline values (Table I). Bicarbonate levels were transiently lower at 30 minutes after CPB, indicating some degree of metabolic acidosis. Hematocrits were generally lower after CPB (Table II), despite transfusions of packed erythrocytes. The concentrations of norepinephrine, epinephrine, and dopamine after CPB did not differ from baseline values (Table II), indicating that the anesthetic regimen was not associated with catecholamine surges. There was no relationship between concentrations of catecholamines and recovery of LV contractility at 60 or 240 minutes.

Global LV function and arterial pressures (Table III). Cardiac output was in general well maintained after CPB, with only a small decrease (24\%) at 120 
Table I. Acid-base status

\begin{tabular}{lccccc}
\hline & $\mathrm{pH}$ & $\mathrm{PCO}_{2}(\mathrm{~mm} \mathrm{Hg})$ & $\mathrm{PO}_{2}(\mathrm{~mm} \mathrm{Hg})$ & $\mathrm{HCO}_{3}^{-}\left(\mathrm{mmol}^{\mathrm{L}}\right)$ & Base excess $(\mathrm{mmol} / \mathrm{L})$ \\
\hline $\begin{array}{l}\text { Pre-CPB/DHCA baseline } \\
\text { Post-CPB/DHCA }\end{array}$ & $7.38 \pm 0.05$ & $31.3 \pm 5.6$ & $290 \pm 133$ & $17.7 \pm 1.8$ & $-5.1 \pm 1.5$ \\
$30 \mathrm{~min}$ & $7.26 \pm 0.08$ & $33.0 \pm 6.7$ & $210 \pm 85$ & $13.9 \pm 1.4^{*}$ & $-11.5 \pm 3.6^{*}$ \\
$60 \mathrm{~min}$ & $7.33 \pm 0.04$ & $30.0 \pm 6.0$ & $244 \pm 100$ & $14.9 \pm 2.1$ & $-8.7 \pm 1.7$ \\
$120 \mathrm{~min}$ & $7.32 \pm 0.07$ & $33.1 \pm 4.1$ & $233 \pm 101$ & $16.4 \pm 2.6$ & $-7.3 \pm 3.7$ \\
$180 \mathrm{~min}$ & $7.33 \pm 0.09$ & $32.4 \pm 9.0$ & $244 \pm 96$ & $16.1 \pm 3.4$ & $-8.1 \pm 3.9^{*}$ \\
$240 \mathrm{~min}$ & $7.34 \pm 0.10$ & $30.4 \pm 6.0$ & $261 \pm 104$ & $16.1 \pm 4.3$ & $-7.7 \pm 5.8$ \\
\hline
\end{tabular}

All data presented as mean \pm standard deviation. $\mathrm{PCO}_{2}$, Partial pressure of carbon dioxide; $\mathrm{PO}_{2}$, partial pressure of oxygen; $\mathrm{HCO}_{3}{ }^{-}$, bicarbonate; $\mathrm{DHCA}$, deep hypothermic circulatory arrest. ${ }^{*} p<0.05$.

Table II. Hematocrits and catecholamines

\begin{tabular}{llccc}
\hline & & \multicolumn{3}{c}{ Catecholamines } \\
\cline { 3 - 4 } & $H c t(\%)$ & $N E(p g / m l)$ & $E(p g / m l)$ & Dopa $(p g / m l)$ \\
\hline Pre-CPB/DHCA baseline & $26 \pm 4$ & $401 \pm 160$ & $187 \pm 106$ & $42 \pm 34$ \\
Post-CPB/DHCA & $19 \pm 4^{*}$ & & \\
$30 \mathrm{~min}$ & $22 \pm 4^{*}$ & $392 \pm 179$ & $204 \pm 159$ & $60 \pm 36$ \\
$60 \mathrm{~min}$ & $26 \pm 7$ & & \\
$120 \mathrm{~min}$ & $23 \pm 3^{*}$ & & & \\
$180 \mathrm{~min}$ & $23 \pm 3^{*}$ & $473 \pm 224$ & $441 \pm 404$ & $70 \pm 42$ \\
$240 \mathrm{~min}$ & & & & \\
\hline
\end{tabular}

All data presented as mean \pm standard deviation. Hct, hematocrit; $N E$, norepinephrine; $E$, epinephrine; Dopa, dopamine; $D H C A$, deep hypothermic circulatory arrest.

${ }^{*} p<0.05$.

Table III. Global cardiac function and arterial pressures

\begin{tabular}{lccccc}
\hline & $C O(\mathrm{ml} / \mathrm{min})$ & $S V(\mathrm{ml})$ & $H R($ beats $/ \mathrm{min})$ & $M A P(\mathrm{~mm} \mathrm{Hg})$ & $M P P(\mathrm{~mm} \mathrm{Hg})$ \\
\hline Pre-CPB/DHCA baseline & $982 \pm 379$ & $5.1 \pm 2.0$ & $195 \pm 25$ & $70.1 \pm 18.2$ & $16.4 \pm 3.1$ \\
Post-CPB/DHCA & & & & \\
$30 \mathrm{~min}$ & $1011 \pm 324$ & $5.7 \pm 1.5$ & $178 \pm 26$ & $43.0 \pm 8.9^{*}$ & $24.3 \pm 5.3^{*}$ \\
$60 \mathrm{~min}$ & $1074 \pm 367$ & $6.1 \pm 2.5^{*}$ & $182 \pm 20$ & $50.7 \pm 5.6^{*}$ & $27.0 \pm 4.7^{*}$ \\
$120 \mathrm{~min}$ & $744 \pm 275^{*}$ & $4.3 \pm 2.0$ & $182 \pm 28$ & $51.7 \pm 5.6^{*}$ & $22.1 \pm 4.2^{*}$ \\
$180 \mathrm{~min}$ & $894 \pm 363$ & $5.2 \pm 2.4$ & $174 \pm 15$ & $48.6 \pm 5.1^{*}$ & $20.9 \pm 3.7^{*}$ \\
$240 \mathrm{~min}$ & $979 \pm 430$ & $5.8 \pm 2.7$ & $171 \pm 13$ & $48.5 \pm 13.5^{*}$ & $19.1 \pm 4.0$ \\
\hline
\end{tabular}

All data presented as mean \pm standard deviation. $C O$, Cardiac output; $S V$, stroke volume; $H R$, heart rate; $M A P$, mean aortic pressure; $M P P$, mean pulmonary artery pressure; $D H C A$, deep hypothermic circulatory arrest. $*_{p}<0.05$.

minutes. Stroke volume was also well maintained, with a slight increase $(20 \%)$ at 60 minutes. Heart rate after CPB did not differ from baseline. During the 4 hours of observation after CPB, mean arterial pressure was decreased to a variable degree, ranging from $26 \%$ to $39 \%$. In contrast, mean pulmonary artery pressure was transiently increased, varying from $48 \%$ at 30 minutes to $27 \%$ at 180 minutes, and had returned to baseline at 240 minutes.

LV systolic function. LV contractility, as assessed by $E_{\text {es }}$ (the slope of the ESPVR), was depressed by $48 \%$ at 30 minutes after CPB, did not differ from baseline between 60 and 180 minutes, and was depressed by $28 \%$ at 240 minutes (Fig. 1). Simultaneously, $\mathrm{V}_{0}$ (the volume intercept) of the ESPVR (5.8 $\pm 2.1 \mathrm{ml}$ at baseline) was shifted to the left at 30 minutes $(4.4 \pm 2.1 \mathrm{ml} ; p<0.05)$ and 240 minutes $(5.0 \pm 1.9 \mathrm{ml} ; p<0.05)$, indicating a pivotal shift in the ESPVR.

LV diastolic function. LV relaxation, as assessed by the time constant $\tau$, was prolonged by $65 \%$ at 30 minutes after $\mathrm{CPB}$, did not differ from baseline between 60 and 180 minutes, and was more mildly prolonged (16\%) at 240 minutes (Fig. 2). LV compliance, assessed by $b$ (the elastic constant of the end-diastolic pressure-volume relationship), and LV 


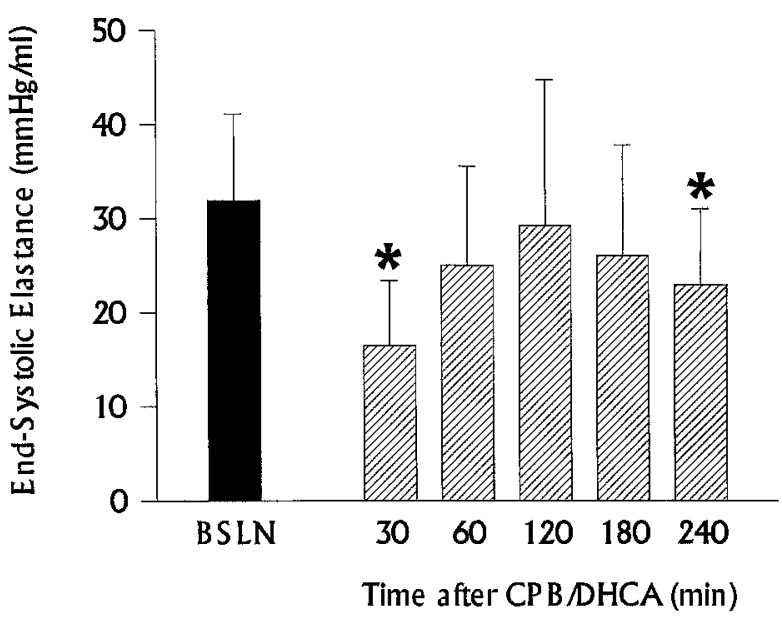

Fig. 1. LV contractility, as assessed by the slope of the ESPVR ( $\mathrm{E}_{\mathrm{es}}$, end-systolic elastance), at baseline (BSLN) and after CBP/deep hypothermic circulatory arrest $(C P B /$ $D H C A$ ). Data presented as mean and standard deviation. Asterisk represents $p<0.05$.

diastolic pressures ( $\mathrm{P}_{\mathrm{ed}}$ and minimum $\mathrm{LV}$ pressure) did not differ from baseline after CPB. LV preload, as assessed by $V_{\text {ed }}$ and left atrial mean pressure, was maintained with volume infusions by study design.

LV afterload. $L V$ afterload, as assessed by $\mathrm{S}_{\mathrm{es}}$, was decreased by $38 \%$ at 30 minutes, was decreased by $24 \%$ at 60 minutes, did not differ from baseline at 120 and 180 minutes, and was again decreased (by $22 \%$ ) at 240 minutes after termination of CPB (Fig. 3).

\section{Discussion}

In deeply anesthetized neonatal lambs, LV contractility and relaxation are markedly depressed after 45 minutes of deep hypothermic circulatory arrest and approximately 60 minutes of reperfusion (30 minutes after termination of CPB). The depression of LV contractility and relaxation is transient with complete recovery between 60-180 minutes after termination of CPB. LV contractility and relaxation were again depressed 240 minutes after $\mathrm{CPB}$, however, albeit to a much lesser degree. In contrast to the effects on contractility and relaxation, static end-diastolic LV compliance was unaffected in this model. In addition, clinically monitored indexes of cardiac function, such as cardiac output and stroke volume, are well maintained after ischemia and reperfusion. A decrease in afterload allows cardiac output to be maintained despite depressed contractility. The presence of LV dysfunc-

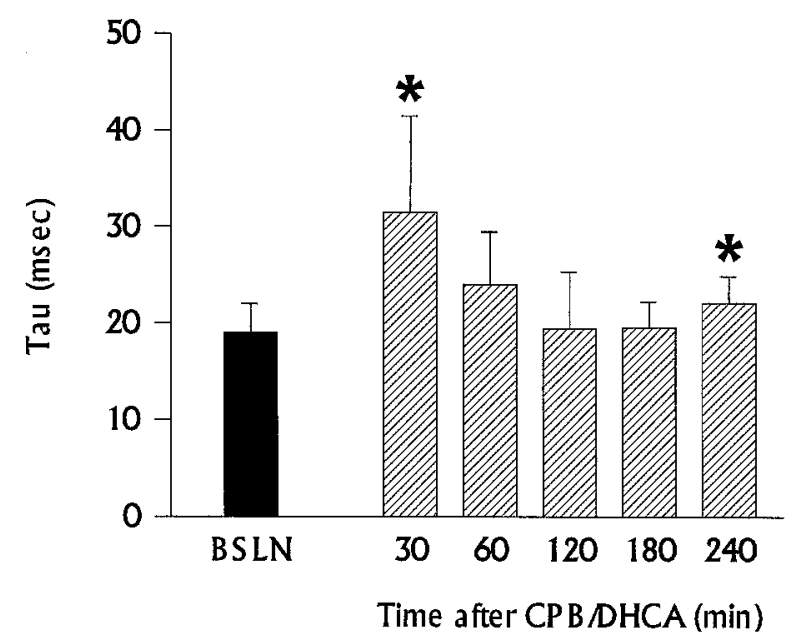

Fig. 2. LV relaxation, as assessed by $\tau$ (the time constant of isovolumic pressure decline), at baseline (BSLN) and after $\mathrm{CPB} /$ deep hypothermic circulatory arrest (CPB) $D H C A$ ). Data presented as mean and standard deviation. Asterisk represents $p<0.05$.

tion detected with relatively load-insensitive indexes of $L V$ contractility $\left(E_{e s}\right)$, would not have been recognized with common clinically monitored and load-sensitive indexes of LV function (cardiac output, stroke volume).

In these neonatal lambs, the use of deep opiate anesthesia with high-dose fentanyl citrate effectively prevents increases in circulating catecholamines after CPB and surgical ischemia. This finding is consistent with previous findings in human neonates. ${ }^{24}$ The measured circulating levels of norepinephrine and dopamine reported in this study were in the normal range for neonatal human beings ${ }^{31}$ and for lambs, ${ }^{32}$ whereas the levels of epinephrine were moderately higher than those in both these species. The levels of epinephrine we found are, however, similar to the preoperative values in human neonates undergoing cardiac operations. ${ }^{24}$ Both the elevated levels of epinephrine and the increased norepinephrine/epinephrine ratio observed in this study may be a result of neurally mediated adrenal medullary release of epinephrine related to the stress of surgical instrumentation. ${ }^{32}$ The levels of epinephrine measured in this study are well below those affecting contractility and causing cardiotoxic effects. ${ }^{33}$ Moreover, much larger increases in circulating catecholamines resulting from CPB and ischemia $^{24,34}$ were prevented in this study, which allowed the assessment of functional recovery from ischemia at similar levels of catecholamine stimula- 


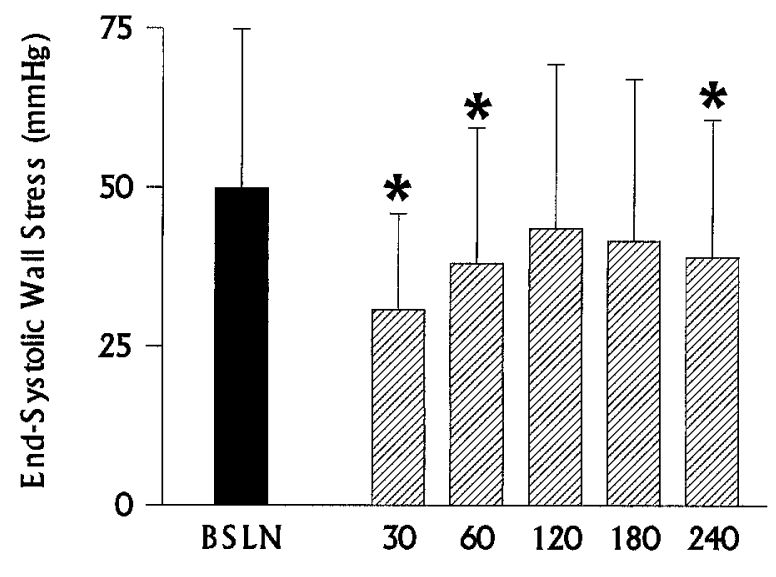

Time after CPB B DHCA (min)

Fig. 3. LV afterload, as assessed by $\mathrm{S}_{\mathrm{es}}$, at baseline $(B S L N)$ and after CPB/deep hypothermic circulatory arrest $(C P B / D H C A)$. Data presented as mean and standard deviation. Asterisk represents $p<0.05$.

tion. Although increased circulating catecholamines may provide short-term compensation for depressed LV contractility caused by myocardial stunning, ${ }^{25}$ catecholamines are most likely ultimately deleterious especially to the neonatal heart. ${ }^{33}$ Human neonates undergoing cardiac operations have improved outcomes when catecholamine surges are prevented by deep opiate anesthesia. ${ }^{24}$ More direct evidence is provided by studies in neonatal pigs exposed to exogenous epinephrine. ${ }^{33}$ On the basis of both functional and ultrastructural observations, cardiotoxicity is more apparent in neonatal myocardium than in adult myocardium. The reason for the increased susceptibility of the neonatal myocardium is unclear but may be related to differences in pharmacokinetics of catecholamines or to developmental differences in cardiac myocytes. Epinephrine and ischemia-reperfusion have several well-established cardiotoxic effects in common, such as oxygen wasting, production of oxygen-derived free radicals, and increased transsarcolemmal calcium ion influx. These effects may amplify each other, similar to the effects of the digitalis glycoside ouabain, which causes an increased transsarcolemmal calcium ion influx and has a deleterious effect on the neonatal myocardium exposed to ischemia. ${ }^{35}$

The findings in this study show interesting similarities to and differences from the findings in studies performed by Blatchford and coworkers ${ }^{18,36}$ in a similar model, in which they used a regimen of relatively light anesthesia with halothane. In these studies, prolonged CPB (120 minutes) ${ }^{18}$ but not brief CPB (65 minutes), ${ }^{36}$ was associated with decreased LV compliance. The addition of cardiac or circulatory arrest to the protocol did not result in further dysfunction. Despite an actual increase in contractility after CPB and arrest, global cardiac function (cardiac output, stroke volume) was depressed. Similarly, in our study, brief CPB (52 minutes) was not associated with changes in $\mathrm{LV}$ compliance. In contrast, in our study, LV contractility was depressed whereas cardiac output and stroke volume were maintained because of simultaneously decreased afterload. The lack of elevated circulating catecholamines in our study may be responsible for these differences. ${ }^{18}$ The presence of several differences in design between these studies, however, does not allow any firm conclusions regarding mechanisms for the discrepancies in the findings. ${ }^{37}$ The finding in our study of well-maintained cardiac output resulting from decreased afterload and occurring despite depressed contractility reemphasizes the clinical importance of evaluating neonates after neonatal cardiac surgery primarily in terms of adequacy of cardiac output, rather than in terms of maintaining some arbitrarily defined blood pressure. In this study, mean and phasic arterial blood pressures were decreased after CPB during the entire 4-hour observation period.

The occurrence of mildly depressed LV contractility and relaxation late (4 hours) after CPB and arrest are compatible with clinical observations and theoretic considerations. In clinical studies in human neonates after repair of a variety of congenital cardiac defects, Starling responses to volume loading were normal within 2 hours of CPB, followed by deterioration of cardiac performance between 4 and 8 hours after CPB.$^{38}$ In children, cardiac output may not be depressed until several hours after operation. ${ }^{39}$ Theoretic considerations for late dysfunction focus on the role of polymorphonuclear leukocytes in the pathogenesis of ischemia-reperfusion injury. Early endothelial cell dysfunction is followed by extravasation of polymorphonuclear leukocytes and late cardiac myocyte injury. This late phase of myocyte injury occurs 4 to 5 hours after reperfusion and is referred to as the "neutrophil amplification" phase. ${ }^{40}$ Also, specific endothelial leukocyte, intercellular, and vascular cell adhesion molecules are maximally expressed 4 to 6 hours after injury. ${ }^{41}$

Two methodologic issues require further discussion. First, because of elevation of pulmonary pressures and reduction of systemic pressures, the rela- 
tionship between right ventricular and $\mathrm{LV}$ pressures changed during the study. This may have affected $\mathrm{LV}$ geometry and the reliability of $\mathrm{V}_{\mathrm{lv}}$ calculations. ${ }^{42}$ To justify our method of $V_{\mathrm{lv}}$ calculation, we compared stroke volume data calculated from dimensional measurements $(\mathrm{SVc})$ with stroke volume data measured with the flow transducer (SVm). We found a consistent relationship $(\mathrm{SVm}=0.6+$ $0.9 \cdot \mathrm{SVc} ; r=0.78$ ) that was independent of pulmonary and systemic arterial pressures. In addition, the small changes in right ventricular afterload are unlikely to have affected LV systolic function. ${ }^{42}$ The other issue relates to the extent of ischemic injury in normal hearts. The duration of ischemia was relatively short, and the postischemic dysfunction was therefore relatively mild and transient. ${ }^{43}$ More significant dysfunction might have been detected in the presence of a longer period of ischemia $^{43}$ or in the presence of associated conditions such as cyanosis, ${ }^{43}$ ventricular hypertrophy, ${ }^{23,37}$ or ventricular dilation. ${ }^{37}$ Congenital heart defects are invariably associated with one or more of these conditions. Future incorporation of these conditions in the model may better define the importance of cardiac dysfunction and the need for cardiotonic drugs after operations for congenital heart disease.

\section{REFERENCES}

1. Hanley FL, Fenton KN, Jonas RA, et al. Surgical repair of complete atrioventricular canal defects in infancy: twenty-year trends. $\mathbf{J}$ THORAC CARdiovasC SURG 1993;106:387-97.

2. Bove EL, Lupinetti FM, Pridjian AK, et al. Results of a policy of primary repair of truncus arteriosus in the neonate. J Thorac Cardiovasc Surg 1993;105:105766.

3. Kirklin JW, Blackstone EH, Jonas RA, et al. Morphologic and surgical determinants of outcome events after repair of tetralogy of Fallot and pulmonary stenosis. J Thorac CARdiovasc Surg 1992;103:70623.

4. Quantz M, Tchervenkov C, Chiu RC. Unique responses of immature hearts to ischemia: functional recovery versus initiation of contracture. J THORAC Cardiovasc SuRg 1992;103:927-35.

5. Nakamura $H$, del Nido PJ, Jimenez E, Sarin M, Feinberg H, Levitsky S. Age-related differences in cardiac susceptibility to ischemia/reperfusion injury: responses to deferoxamine. $\mathbf{J}$ THORAC CARDIOVASC SURG 1992;104:165-72.

6. Baker JE, Boerboom LE, Olinger GN. Age-related changes in the ability of hypothermia and cardioplegia to protect ischemic rabbit myocardium. J THORAC CARdiovasc Surg 1988;96:717-24.
7. Avkiran M, Hearse DJ. Protection of the myocardium during global ischemia: is crystalloid cardioplegia effective in immature myocardium? J THORAC CARDIOVASC SURG 1989;97:220-8.

8. Yano Y, Braimbridge MV, Hearse DJ. Protection of the pediatric myocardium: differential susceptibility to ischemic injury of the neonatal rat heart. J THORAC Cardiovasc Surg 1987;94:887-96.

9. Grice WN, Konishi T, Apstein CS. Resistance of neonatal myocardium to injury during normothermic and hypothermic ischemic arrest and reperfusion. Circulation 1987;76(Suppl 5):V150-5.

10. Watanabe H, Yokosawa T, Eguchi S, Imai S. Difference in the mechanical response to a cardioplegic solution observed between the neonatal and the adult guinea pig myocardium. J THorac CARdiovasc SuRG 1989;97:59-66.

11. Wittnich C, Peniston C, Ianuzzo D, Abel JG, Salerno TA. Relative vulnerability of neonatal and adult hearts to ischemic injury. Circulation 1987;76(Suppl 5):V156-60.

12. Hosseinzadeh T, Tchervenkov CI, Quantz M, Chiu RC. Adverse effect of prearrest hypothermia in immature hearts: rate versus duration of cooling. Ann Thorac Surg 1992;53:464-71.

13. Rebeyka IM, Diaz RJ, Augustine JM, et al. Effect of rapid cooling contracture on ischemic tolerance in immature myocardium. Circulation 1991;84(Suppl 3): III389-93.

14. Bove EL, Stammers AH, Gallagher KP. Protection of the neonatal myocardium during hypothermic ischemia: effect of cardioplegia on left ventricular function in the rabbit. J Thorac Cardiovasc Surg 1987; 94:115-23.

15. Watanabe H, Yokosawa T, Eguchi S, Imai S. Functional and metabolic protection of the neonatal myocardium from ischemia: insufficient protection by cardioplegia. J Thorac Cardiovasc Surg 1989;97:50-8.

16. Bull C, Cooper J, Stark J. Cardioplegic protection of child's heart. J ThORAC CARdiovasC SuRG 1984;88: 287-93.

17. Fujiwara T, Heinle J, Britton L, Mayer JE. Myocardial preservation in neonatal lambs: comparison of hypothermia with crystalloid and blood cardioplegia. J Thorac Cardiovasc Surg 1991;101:703-12.

18. Blatchford JW, Barragry TP, Lillehei TJ, Ring WS. Effects of cardioplegic arrest on left ventricular systolic and diastolic function of the intact neonatal heart. J Thorac Cardiovasc Surg 1994;107:527-35.

19. Wilson IC, DiNatale JM, Gillinov AM, Curtis WE, Cameron DE, Gardner TJ. Leukocyte depletion in a neonatal model of cardiac surgery. Ann Thorac Surg 1993;55:12-9.

20. Ganzel BL, Katzmark SL, Mavroudis C. Myocardial preservation in the neonate: beneficial effects of cardioplegia and systemic hypothermia on piglets 
undergoing cardiopulmonary bypass and myocardial ischemia. J THORAC CARdiovasc Surg 1988;96: 414-22.

21. Coles JG, Watanabe T, Wilson GJ, et al. Age-related differences in the response to myocardial ischemic stress. J Thorac CardiovasC Surg 1987;94:526-34.

22. Clark BJ, Woodford EJ, Malec EJ, Norwood CR, Pigott JD, Norwood WI. Effects of potassium cardioplegia on high-energy phosphate kinetics during circulatory arrest with deep hypothermia in the newborn piglet heart. J THORAC CARDIOVASC SURG 1991;101: $342-9$.

23. Del Nido PJ, Benson LN, Mickle DAG, Kielmanowicz S, Coles JG, Wilson GJ. Impaired left ventricular postischemic function and metabolism in chronic right ventricular hypertrophy. Circulation 1987;76(Suppl 5):V168-73.

24. Anand KJ, Hickey PR. Halothane-morphine compared with high-dose sufentanil for anesthesia and postoperative analgesia in neonatal cardiac surgery. N Engl J Med 1992;326:1-9.

25. Ellis SG, Wynne J, Braunwald E, Henschke CI, Sandor T, Kloner RA. Response of reperfusionsalvaged, stunned myocardium to inotropic stimulation. Am Heart J 1984;107:13-9.

26. Little WC, Cheng CP, Peterson T, Vinten-Johansen J. Response of the left ventricular end-systolic pressurevolume relation in conscious dogs to a wide range of contractile states. Circulation 1988;78:736-45.

27. Weiss JL, Frederiksen JW, Weisfeldt ML. Hemodynamic determinants of the time-course of fall in canine left ventricular pressure. J Clin Invest 1976;58: 751-60.

28. Little WC, Downes TR, Applegate RJ. Invasive evaluation of left ventricular diastolic performance. Herz 1990;15:362-76.

29. Brodie BR, McLaurin LP, Grossman W. Combined hemodynamic-ultrasonic method for studying left ventricular wall stress: comparison with angiography. Am J Cardiol 1976;37:864-70.

30. Zar JH. Biostatistical analysis. Englewood, New Jersey: Prentice-Hall, 1984.

31. Eliot RJ, Lam R, Leake RD, Hobel CJ, Fisher DA. Plasma catecholamine concentrations in infants at birth and during the first 48 hours of life. J Pediatr 1980;96:311-5.

32. Padbury JF, Diakomanolis ES, Hobel CJ, Perelman
A, Fisher DA. Neonatal adaptation: sympatho-adrenal response to umbilical cord cutting. Pediatr Res 1981;15:1483-7.

33. Caspi J, Coles JG, Benson $\mathrm{LN}$, et al. Age-related response to epinephrine-induced myocardial stress: a functional and ultrastructural study. Circulation 1991; 84(Suppl 3):III394-9.

34. Wood M, Shand DG, Wood AJ. The sympathetic response to profound hypothermia and circulatory arrest in children. Canad Anaesth Soc J 1980;27:125-31.

35. Konishi T, Apstein CS. Deleterious effects of digitalis on newborn rabbit myocardium after simulated cardiac surgery. J Thorac Cardiovasc Surg 1991;101:337-41.

36. Blatchford JW, Barragry TP, Lillehei TJ, Tuna IC, Ring WS. Cardioplegic arrest versus profoundly hypothermic arrest in the neonate. Surg Forum 1987;38: 236-8.

37. Lupinetti FM. Ischemia of the neonatal heart. In: Piper HM, Preusse CJ, eds. Ischemia-reperfusion in cardiac surgery. Norwell, Massachusetts: Kluwer Academic Publishers, 1993:81-103.

38. Burrows FA, Williams WG, Teoh KH, et al. Myocardial performance after repair of congenital defects in infants and children: response to volume loading. J Thorac Cardiovasc Surg 1988;96:548-56.

39. Covitz W, Eubig C. Nuclear indicators of cardiac function after open-heart surgery. Appl Radiol 1980; 117-22.

40. Albertine $\mathrm{KH}$, Warwick AS, In-lang $\mathrm{M}$, Leer DJ, Becker LC, Leer AM. Quantification of neutrophil migration following myocardial ischemia and reperfusion in cats and dogs. J Leukon Bill 1994;55:55766.

41. Sluiter W, Pietersma A, Lamers JM, Koster JF. Leukocyte adhesion molecules on the vascular endothelium: their role in the pathogenesis of cardiovascular disease and the mechanisms underlying their expression. J Cardiovasc Pharmacol 1993;22(Suppl 4):S37-44.

42. Olsen CO, Tyson GS, Maier GW, Spratt JA, Davis JW, Rankin JS. Dynamic ventricular interaction in the conscious dog. Circ Res 1983;52:85-104.

43. Julia P, Kofsky ER, Buckberg GD, Young HH, Bugyi HI. Studies of myocardial protection in the immature heart: models of ischemic and hypoxic/ischemic injury in the immature puppy heart. J THORAC CARDIOvASC SURG 1991;101:14-21. 